\title{
Smoking and Periodontal Disease
}

\author{
Tea Borojevic \\ Pliva, Zagreb, Croatia \\ Corresponding author: Tea Borojevic, MDD, Pliva, Zagreb, Croatia. E-mail: tea5bor@yahoo.com
}

\section{REVIEW}

ABSTRACT

Periodontitis is a group of inflammatory diseases affecting the supporting tissues of the tooth (periodontium). The periodontium consists of four tissues : gingiva, alveolar bone and periodontal ligaments. Tobbaco use is one of the modifiable risk factors and has enormous influance on the development, progres and tretmen results of periodontal disease. The relationship between smoking and periodontal health was investigated as early as the miiddle of last century. Smoking is an independent risk factor for the initiation, extent and severity of periodontal disease. Additionally, smoking can lower the chances for successful tretment. Tretmans in patients with periodontal disease must be focused on understanding the relationship between genetic and environmental factors. Only with individual approach we can identify our pacients risks and achieve better results. Key words: smoking, periodontal disease.

\section{INTRODUCTION}

Periodontitis is a group of inflammatory diseases affecting the supporting tissues of the tooth (periodontium). The periodontium consists of four tissues : gingiva, alveolar bone and periodontal ligaments.

The periodontal diseases are highly prevalent and can affect up to $90 \%$ of the world wide population. Gingivitis, the mildest form of periodontal disease, is caused by the bacterial biofilm (dental plaque) that accumulates on teeth adjacent to the gingiva (gums).

The simtoms are usualy red, swollen gums who can bleed easily. However, gingivitis does not affect the underlying supporting structures of the teeth and is reversible. When gingivitis is not treated, it can advanece to periodontitis. Periodontitis results in loss of connective tissue and bone support and is a major cause of tooth loss in adults (1). In addition to pathogenic microorganisms in the biofilm, genetic and environmental factors has enormouse influence on development periodontal disease.Tobbaco use is one of the modifiable risk factors and has enormous influance on the development, progres and tretmen results of periodontal disease.

The American Academy of Periodontology (AAP) has classified periodontitis into aggressive periodontitis (AgP), chronic periodontitis (CP) and periodontitis as a manifestation of systemic diseases (2). Both AgP and CP have a multi-factorial etiology with dental plaque as the initiating factor (3). However the initiation and progression of periodontitis are influenced by other factors including tobbaco use.

\section{RELATIONSHIP BETWEEN SMOKING AND PERIODONTAL DISEASE}

One-third of the world's adult population are smokers ( $57 \%$ of these are men, $43 \%$ are women) . It is predicted that in 20 years this yearly death rate from tobacco use will be more than 10 million people. Smoking in developing countries is rising by more than $3 \%$ a year (4). We can assume periodontal diseasees will also rise.

The relationship between smoking and periodontal health was investigated as early as the miiddle of last century. Smoking is an independent risk factor for the initiation, extent and severity of periodontal disease. Additionally, smoking can lower the chances for successful tretment. (Figure 1,2,3,4).

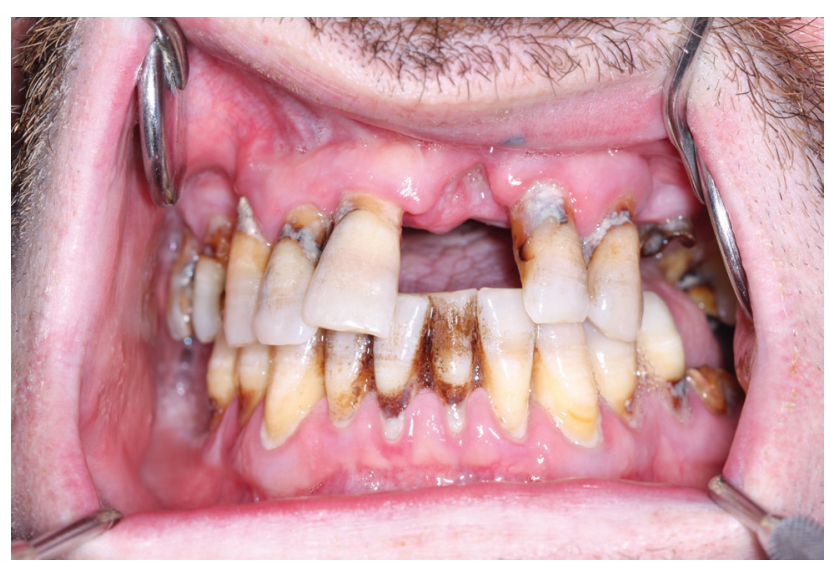

Figure 1. Generalized advanced chronic periodontitis in smooker 


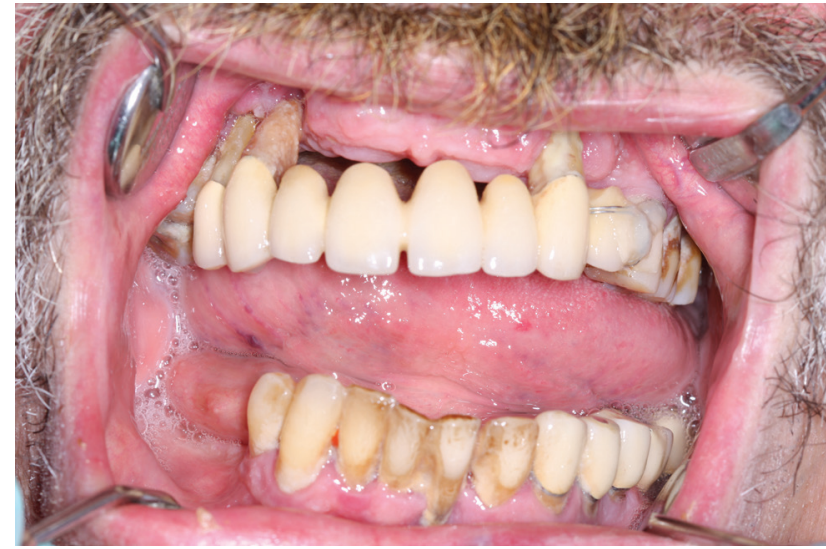

Figure 2. Generalized advanced chronic periodontitis in smooker

Cross-sectional and longitudinal data provide strong support for the statement that the risk of developing periodontal disease as measured by clinical attachment loss and alveolar bone loss increases with increased smoking. Studies find that former smokers (clinically defined as two or more years since quitting smoking) experience less attachment loss than current smokers but more than neversmokers. Furthermore, the likelihood of developing increasing periodontal disease exhibits dose dependency (5)

For many years sciences did not know how smoking sight into the established clinical conundrum of increased infection with periodontal pathogens but reduced clinical inflammation in smokers.

Bagaitkar and asos. established that exposure of P. gingivalis to tobacco smoke extract increased the expression of the major fimbrial antigen (FimA), but not the minor fimbrial antigen (Mfa1). That means that exposure did not induce P. gingivalis auto-aggregation but did promote dual species biofilm formation, monitored by microcolony numbers and depth. Interestingly, P. gingivalis biofilms grown in the presence of tobacco smoke exhibited a lower pro-inflammatory capacity (TNF- $\alpha$, IL-6) than control biofilms. The underlying mechanisms are unknown,more likely tobacco smoke represents an environmental stress to which P. gingivalis adapts by altering the expression of several virulence factors-including major and minor fimbrial antigens (FimA and Mfa1, respectively) and capsule-concomitant with a reduced pro-inflammatory potential of intact $\mathrm{P}$. gingivalis $(7,8)$.

In vitro studies have shown altered gingival crevicular fluid inflammatory cytokine profiles (GCF), immune cell function and altered proteolylic regulation in smokers.

Smokers exhibited a decrease in several pro-inflammatory cytokines and chemokines and certain regulators of T-cells and NK-cells. This reflects the immunosup-

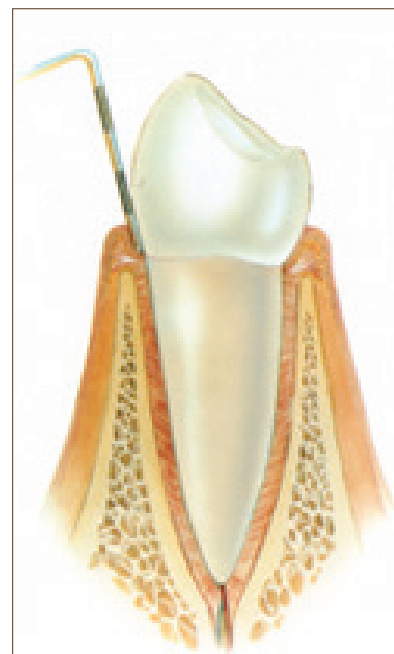

Healthy gums

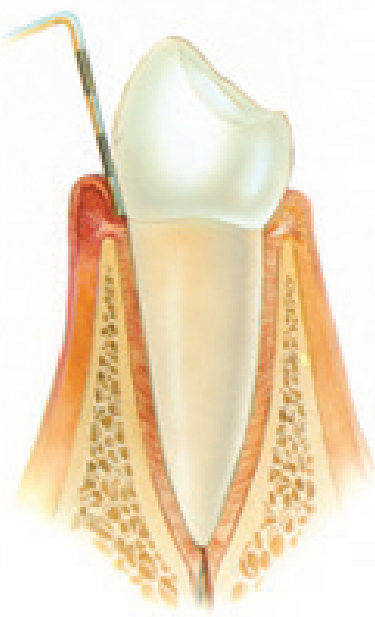

Gingivitis (swollen gums)
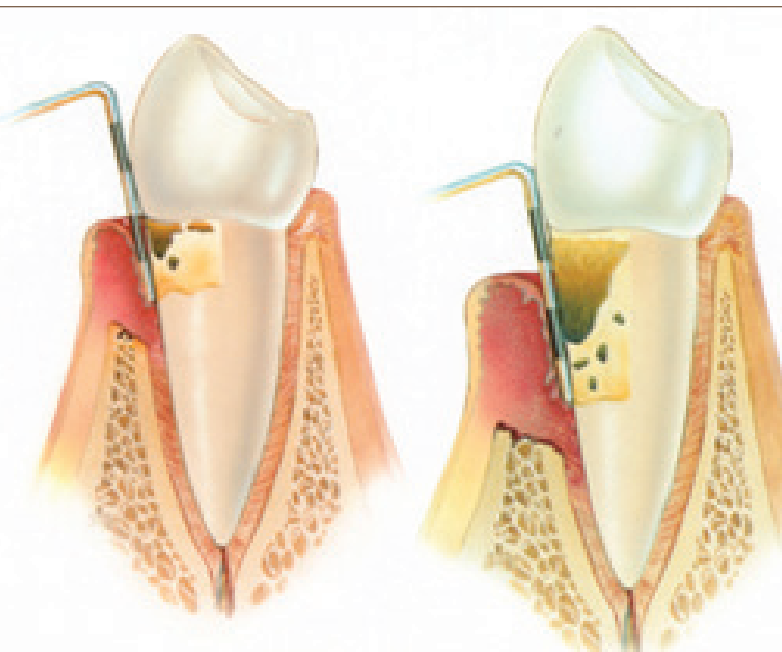

Moderate Periodontitis

Advanced Periodontitis (bone loss + gum pocket) (bone loss + gum pocket)

Figure 3. Progression of periodontal disease :http://www.stcatherinesdentalpractice.co.uk/dental-treatments-in-grantham/ periodontal-treatment-in-grantham.html

affect periodont and why people with chronical periodontitis have reduced clinical inflammation.Today we know that tobacco smoke induces alterations to the 3-OH fatty acids present in lipid $\mathrm{A}$ in a manner consistent with a microflora of reduced inflammatory potential.

In investigation smookers had significant reductions in the 3-OH fatty acids associated with the consensus (high potency) enteric LPS structure were noted in smokers compared with non-smokers with chronic periodontitis. Thus, smoking is associated with specific structural alterations to the lipid-A-derived 3-OH fatty acid profile in saliva that are consistent with an oral microflora of reduced inflammatory potential.(6)

These findings provide much-needed mechanistic in- pressant effects of smoking which may contribute to an enhanced susceptibility to periodontitis (9).

Periodontal treatment tends to be less likely to be successful in smokers than in non-smokers. Studies evaluating the efficacy of periodontal disease control and specific periodontal procedures including regenerative procedures, soft tissue grafting procedures and implant procedures have consistently demonstrated a negative effect from smoking on success rates(10).

\section{CONCLUSION}

Smoking is well-established risk factor for periodontal disease. It changes the humen microflora, humen immune response that leads to destruction of the support- 
ing tissues of the tooth. Difficult circumstance is a fact that simptoms in periodontal disease in smookers are increased so It can take years before the patient seeks help, then it is often too late.

Tretmans in patients with periodontal disease must be focused on understanding the relationship between genetic and environmental factors. Only with individual approach we can identify our pacients risks and achieve better results.

\section{REFERENCES}

1. Armitage GC. Development of a classification system for periodontal disease and conditions. Ann Periodontol. 1999; 4: 1-6. doi: 10.1902/annals.1999.4.1.1. Page RC, Offenbacher S, Schroeder HE, Seymour GJ, Kornman KS. Advances in the pathogenesis of periodontitis: summary of developments, clinical implications and future directions. Periodontol 2000. 1997; 14: 216-248. doi: 10.1111/j.1600-0757.1997.tb00199.x.

2. Pihlstrom BL, Michalowicz BS, Johnson NW. Periodontal disease. The Lancet. 2005; 366(9499): 1809-1820.

3. Bagaitkar J, Daep CA, Patel CK, Renaud DE, Demuth DR, Scott DA. Tobacco smoke augments Porphyromonas gingivalis-Streptococcus gordonii biofilm formation. PLoS One. 2011; 6(11): e27386.
4. Hayman L, Steffen MJ, Stevens J. Smoking and periodontal disease: discrimination of antibody responses to pathogenic and commensal oral bacteria. Clin Exp Immunol. 2011; 164(1): 118-126.

5. Buduneli N, Larsson L, Biyikoglu B, Renaud DE, Bagaitkar J, Scott DA. Fatty acid profiles in smokers with chronic periodontitis. J Dent Res. 2011; 90(1): 47-52.

6. http://www.medicalnewstoday.com/releases/9702.php

7. http://dentalstudynotes.pgpreparation.in/2007/12/periodontitis.html

8. Tomar SL, Asma S. Smoking-attributable periodontitis in the United States: findings from NHANES III. National Health and Nutrition Examination Survey. J Periodontol. 2000; 71(5): 743-751.

9. Tymkiw KD, Thunell DH, Johnson GK, Joly S, Burnell KK, Cavanaugh JE, Brogden KA, Guthmiller JM. Influence of smoking on gingival crevicular fluid cytokines in severe chronic periodontitis J Clin Periodontol. 2011 Mar; 38(3): 219-228. doi: 10.1111/j.1600-051X.2010.01684.x.

10. Bagaitkar J, Demuth DR, Daep CA, Renaud DE, Pierce DL, Scott DA P. gingivalis fimbrial proteins which induce TLR2 hyposensitivity. PLoS One. 2010; 5(5): e9323..

\section{About EUPHA}

Public Health in Europe

Members

EUPHA Sections

EUPHA Conferences

European Journal of Public Health

EUPHA Publications

\section{EUPHApedia}

Projects

Links

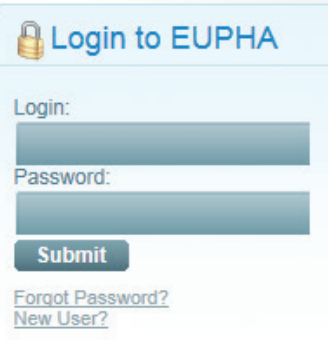

\section{The European Public Health Association}

The European Public Health Association, or EUPHA in short, is an umbrella organisation for public health associations in Europe. EUPHA was founded in 1992. EUPHA is an international, multidisciplinary, scientific organisation, bringing together around 14000 public health professionals for professional exchange and collaboration throughout Europe. We encourage a multidisciplinary approach to public health.

$\rightarrow$ Read More

Conferences

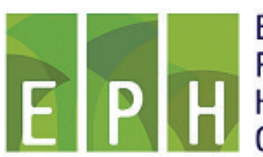

EUROPEAN

PUBLIC

HEALTH CONFERENCE

The next EUPHA conference for 2012 is themed 'All Inclusive Public Health' and will be held in St. Julian's, Malta

In partnership with:

- Association of Schools of Public Health in the European Region (ASPHER)

- Malta Association of Public Health Medecine (MAPHM)

$\rightarrow$ Read More
News

14 September, 2012

WHO/EURO Regional Committee adopted the European Action Plan for Strengthening Public Health Capacities and Services at its 62 nd session that concluded yesterday in Malta. Read more.

05 September, 2012

The EUPHA August newsletter is distributed to the newsletter subscribers. If you are interested, login to the database and set your newsletter box to YES. Read more.

03 September, 2012

EUPHA to attend the annual meeting of the German Society of Social Medicine and Prevention! Read more...

05 July, 2012

Going down memory lane - 20 years of EUPHA in pictures

Click here for the latest addition. Read more.

29 June, 2012 